\title{
Epigenetic Modifications in Myeloma: Focused Review of Current Data and Potential Therapeutic Applications
}

\author{
Suvir Singh ${ }^{1}$ Kunal Jain ${ }^{2}$ Rintu Sharma ${ }^{1}$ Jagdeep Singh ${ }^{2}$ Davinder Paul ${ }^{2}$ \\ ${ }^{1}$ Department of Clinical Hematology and Stem Cell Transplantation, \\ Dayanand Medical College, Ludhiana, Punjab, India \\ 2 Department of Medical Oncology, Dayanand Medical College, \\ Ludhiana, Punjab, India \\ Address for correspondence Suvir Singh, MD, DM, Department of \\ Clinical Haematology, Haemato-Oncology and Bone Marrow (Stem \\ Cell) Transplantation, Dayanand Medical College, Ludhiana, 141001, \\ Punjab, India (e-mail: suvirs@gmail.com).
}

Ind J Med Paediatr Oncol 2021;42:395-405.

\begin{abstract}
Keywords

- myeloma

- lenalidomide

- pomalidomide

- transplant

- relapse

Multiple myeloma is a common hematologic malignancy with an incidence of 1 per 100,000 population and is characterized by a nearly $100 \%$ risk of relapse, necessitating treatment with newer therapeutic agents at each instance of progression. However, use of newer agents is often precluded by cost and accessibility in a resourceconstrained setting. Description of newer pathways of disease pathogenesis potentially provides opportunities for identification of therapeutic targets and a better understanding of disease biology. Identification of epigenetic changes in myeloma is an emerging premise, with several pathways contributing to pathogenesis and progression of disease. Greater understanding of epigenetic alterations provides opportunities to detect several targetable enzymes or pathways that can be of clinical use.
\end{abstract}

\section{Introduction}

Epigenetics is defined as heritable changes in genetic function that occur without alteration of the underlying genetic code. Since its original description, it is now clear that epigenetic mechanisms are vital for cellular growth, development, and establishment of a distinct cellular identity. ${ }^{1}$ The term "epigenome" describes the epigenetic regulatory mechanisms across the entire genome; and unlike the genome, it varies across different cell types. Abnormalities in epigenetic control can lead to a wide variety of cellular dysfunction, and have been specifically found to contribute to carcinogenesis. ${ }^{2}$ Epigenetic alterations are early events in the pathogenesis of certain cancers and contribute to disease progression, analogous to clonal cytogenetic evolution. $^{3}$ Epigenetic modifications are of interest in several malignancies, and have been utilized most notably for the treatment of acute myeloid leukemia in the form of hypomethylating agents. Significant molecular data are also emerging on the role of epigenetics for several other malignancies, and is of specific importance in multiple myeloma (MM).

MM is a common hematologic malignancy with a universal risk of relapse and has undergone advances in survival over the past two decades. ${ }^{4}$ However, it still carries a nearly $100 \%$ risk of relapse, necessitating newer agents to be initiated at each instance of progression. ${ }^{5}$ As a result, no functional cure is defined, and therapy must continue indefinitely. Although several newer novel agents have been introduced in the past 5 years, costs continue to be prohibitive, especially in resource constrained settings. ${ }^{6}$ Thus, there is an ongoing need to identify newer cellular pathways and targetable genetic
DOI https://doi.org/ 10.1055/s-0041-1732861. ISSN 0971-5851.

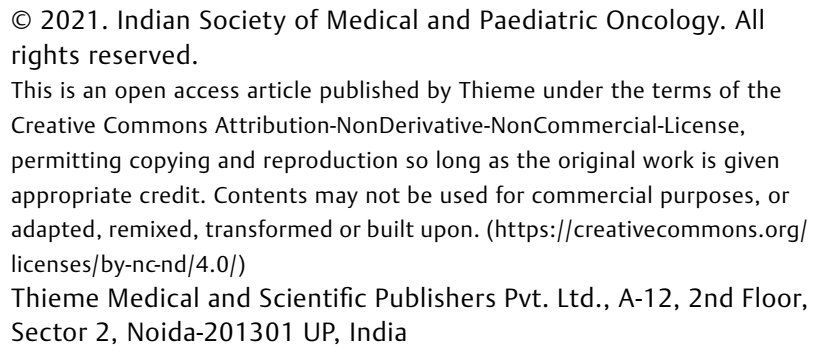

This is an open access article published by Thieme under the terms of the Creative Commons Attribution-NonDerivative-NonCommercial-License, permitting copying and reproduction so long as the original work is given appropriate credit. Contents may not be used for commercial purposes, or adapted, remixed, transformed or built upon. (https://creativecommons.org/ licenses/by-nc-nd/4.0/) Thieme Medical and Scientific Publishers Pvt. Ltd., A-12, 2nd Floor, Sector 2, Noida-201301 UP, India 
lesions to ensure the availability of treatment options at each relapse.

Epigenetic mechanisms have recently emerged as critical mediators of disease pathogenesis and progression in myeloma. Several mechanisms are linked to drug responsiveness and known to modify survival. As seen in the case of acute myeloid leukemia (AML), several components of epigenetic mechanisms are eminently targetable and will likely offer an opportunity for a new approach to drug development. An added impetus for studying epigenetic pathways would be definition of differences in disease biology based on geographic variation. For instance, significant differences in age of incidence of myeloma have been noted in Indian patients compared with Western data, with higher likelihood of end organ damage at diagnosis. ${ }^{7}$

We provide a succinct snapshot of the current role of epigenetic mechanisms in disease pathogenesis in MM, and highlight potential therapeutic applications. We also provide a snapshot of potential drug targets and current ongoing trials targeting epigenetic pathways in MM.

\section{Summary of Basic Mechanisms of Epigenetic Control}

Epigenetic control is facilitated by several biochemical processes, of which the best understood mechanisms are (a) DNA methylation, (b) histone modification, and (c) microRNA (miRNA) expression. These three processes are most widely described and are targets of several investigational approaches to treatment.

\section{DNA Methylation}

DNA methylation consists of addition of a methyl group to the 5 ' carbon of cytosine on DNA. The cytosine bases that are involved in methylation are usually located in regulatory (enhancer or repressor) sequences, and can recruit other proteins to functionally silence downstream genes. ${ }^{8}$ DNA methylation of promotor genes, therefore, leads to silencing of the downstream genes regulated with the same. DNA methylation is performed by enzymes called DNA methyl transferases (DNMT) and typically occurs at sites of $\mathrm{CpG}$ (cytosine-phosphate-guanine) dinucleotides, which are concentrated in sites known as CpG islands, mostly at 5 ' ends of DNA. ${ }^{8}$ There are 28 million CpGs in the human genome, and $\sim 60 \%$ to $80 \%$ are methylated.

\section{Histone Modification}

Intracellular DNA is tightly wound around proteins called histones, which are octamers consisting of eight subunits. This process is best summarized by its original definition given in the 1960s, "dynamic and reversible mechanism for activation as well as repression of RNA synthesis." ${ }^{9}$ It is known that modification of histone proteins by biochemical changes enables regulation of DNA expression by increasing or decreasing chromatin accessibility. The first mechanism to be elucidated was histone acetylation and deacetylation, following which several other mechanisms have been described over the last decade. ${ }^{10}$ As genetic regulation needs to be reversible and dynamic, most of the processes are reversible and involve reciprocal "effector" and "eraser" enzymes. These include acetylation, methylation, and phosphorylation, and the use of so-called "erasers," or enzymes with reciprocal activity to the ones above. - Fig. 1 summarizes the basic process of histone modification.

\section{Noncoding RNA Expression}

Noncoding (ncRNAs) are RNAs that are not coded into proteins. They are classified by their size into small and large (a)

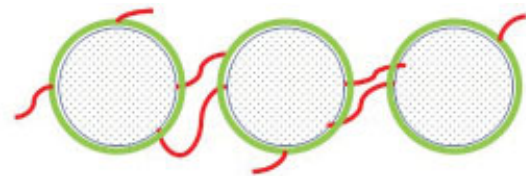

(b)

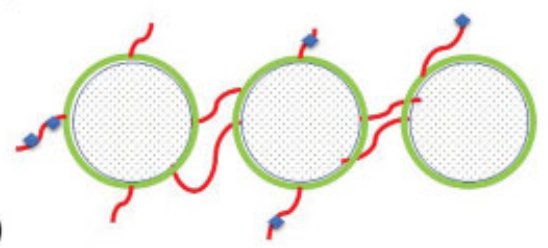

(c)

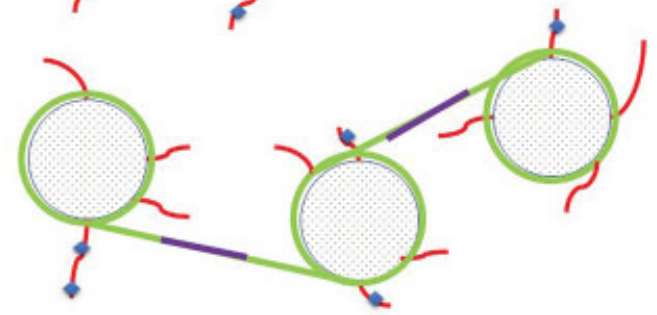

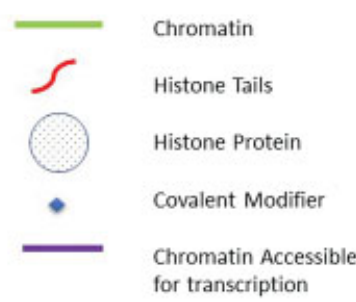

(a): Chromatin is usually tightly wound around histone proteins, precluding access to transcriptional machinery. Histone tails act as sites of covalent modification and also enable histone-histone interactions

(b): Binding of a covalent modifier, either an acetyl or a methyl group to the histone tails initiates a change in binding properties of chromatin to histones

(c): After conformational change, chromatin is available in an open form and accessible to transcription factors

Fig. 1 Histone modifications in DNA. Histone proteins (dotted blue) are tightly wound to DNA (green), preventing access of transcriptional machinery. Reversible binding of covalent modifiers can occur either on the histone protein core or on one of the histone tails (red). Binding or a modifier, for example, an acetyl group (blue), leads to a conformational change, opening the chromatin structure and enabling access to transcriptional machinery. 


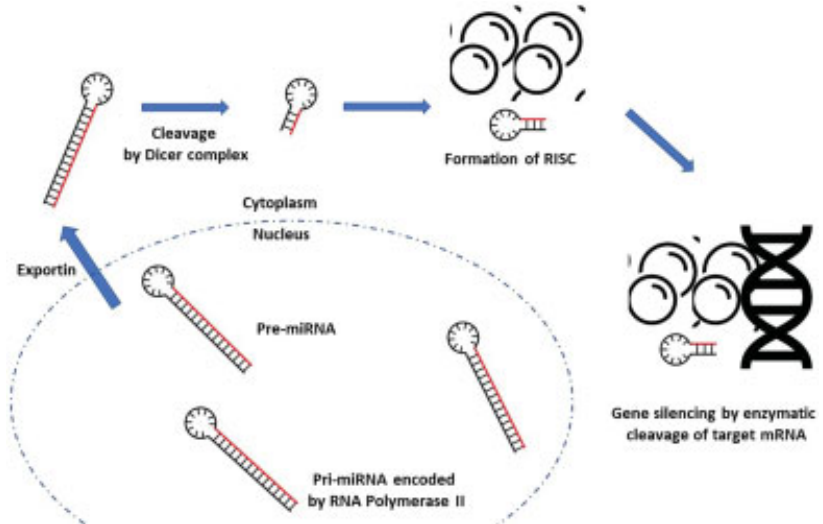

Fig. 2 Summary of micro-RNA (miRNA)-mediated control of genetic expression. Starting from lower left, RNA polymerase II encodes primary miRNA (pri-miRNA) that is converted to pre-miRNA and exported out of the nucleus by Exportin. After cleavage by the Dicer (helicase with RNase motif) complex, the miRNA forms an RNAinduced silencing complex (RISC) that binds to complementary miRNA, silencing its expression. This repressor function of miRNA against has demonstrated antimyeloma activity in vitro.

ncRNAs. The small ncRNAs include miRNA, piwi interacting RNA, transfer RNA, and small nucleolar RNA. ${ }^{11}$ They are involved in regulation of DNA expression by several mechanisms, out of which epigenetic alteration is one of them. - Fig. 2 summarizes mechanisms of miRNA control with potential therapeutic interest.

\section{Genetic Changes in Myeloma}

Plasma cell (PC) clones in MM acquire several genetic abnormalities while progressing from the stage of monoclonal gammopathy of undetermined significance (MGUS) to symptomatic disease. Broadly, these are categorized as primary and secondary cytogenetic abnormalities. Primary cytogenetic abnormalities arise at the stage of MGUS and have a significant impact on disease phenotype, organ damage, and rate of progression. These are mutually exclusive, with each clone having only one primary cytogenetic anomaly. ${ }^{12}$ Common primary genetic changes include hyperdiploidy and immunoglobulin heavy chain promotor ( $\mathrm{IgH})$ translocations. Hyperploidy of at least one odd numbered chromosome is noted in a majority of patients with myeloma, commonly presenting as trisomy. ${ }^{13}$ IgH translocations are usually a result of errors in DNA modification as a part of physiological processes of $\mathrm{V}(\mathrm{D}) \mathrm{J}$ recombination and class switching. These translocations commonly place an oncogene under control of the highly active IgH locus. ${ }^{14}$ Both these changes can be observed in PCs at all stages of disease, indicating the fundamental nature of these changes.

Recent advances in next-generation sequencing (NGS) have also identified several patterns of single gene mutations in patients with newly diagnosed myeloma. Mutations in BRAF, TP53, KRAS, NRAS, and DIS3 are some of the commonest recurrently mutated genes. Single gene mutations have already been used to classify patients into groups with distinct phenotypes and open up avenues for individualized medicine. ${ }^{15}$
On the other hand, secondary cytogenetic abnormalities arise at the time of disease progression and clonal evolution, with each cell possibly having multiple secondary abnormalities. In routine practice, either of these can be detected in $~ 50 \%$ of patients by conventional karyotyping and 40 to $50 \%$ by fluorescence in situ hybridization. ${ }^{16}$ Commonly described secondary cytogenetic abnormalities include del(17p), gain (1q), and myc translocations.

\section{Summary of Epigenetic Changes in Myeloma}

All three epigenetic processes, namely DNA methylation, histone modification, and miRNA processing, are active in MM. The following text is a summary of each of these processes.

\section{DNA Methylation}

\section{DNA Methylation in Myeloma Is Heterogeneous}

The potential role for DNA methylation in MM was elucidated in 2004, when it was shown that methylation of promoter regions of tumor suppressor genes (leading to inactivation) was increased in patients with MM. ${ }^{17}$ Subsequently, it has been observed that the pattern of genome methylation in myeloma is not uniform, and consists of specific hypo- and hypermethylated regions. Several in vitro studies have highlighted differential effects of methylation at different stages in the pathogenesis of myeloma. As with several solid organ malignancies, the overall methylation pattern in initial phase consists of hypermethylation, with advanced myeloma demonstrating global DNA hypomethylation, reflecting genomic instability. ${ }^{18,19}$ DNA hypomethylation is postulated to activate several transcriptional units or oncogenes that are usually repressed and provide a survival advantage. ${ }^{20}$ Hypomethylation is frequently observed on repetitive DNA elements and progressively increases while moving from healthy controls to myeloma to PC leukemia. ${ }^{21}$ It is essential to note that global hypomethylation is not uniform, and several loci are hypermethylated in advanced or relapsed disease. ${ }^{22}$ Interestingly, DNA methylation in MM and MGUS has been seen to occur at sites distant from $\mathrm{CpG}$ rich promoters, specifically in areas known for binding to $\mathrm{B}$ cell promotors. ${ }^{18}$ This presents a new area of potential research, as these promotors may have a role in driving myeloma cell proliferation and may be targetable by newer therapies.

Unlike methylation, no single mechanism describes the process of hypomethylation. The simplest method described is lack of maintenance of methylation, which occurs with downregulation of DNMT. These changes mirror alterations in enzymes mediating DNA methylation, that is, DNMT1, which is shown to increase in expression when moving from MGUS to symptomatic disease. ${ }^{21}$ Expression of DNMT3a has been shown to be downregulated in patients with MGUS and $\mathrm{MM}$, reducing baseline maintenance methylation. ${ }^{23}$ Putative biochemical mechanisms of DNA hypomethylation are still not clear and are summarized in this excellent review. ${ }^{24}$ These mechanisms are clinically relevant as myeloma cell lines are susceptible to DNMT inhibition with currently available hypomethylating agents, providing a potential therapeutic target. 


\section{MicroRNA}

\section{Diverse Changes in miRNA Expression Characterize Myeloma}

miRNAs were first identified in 1993, defined as small molecules with antisense $3^{\prime}$ UTR specificity. ${ }^{25}$ It was later identified that miRNAs are small, ncRNAs that regulate gene expression at the posttranslational level. Depending on their location, miRNAs are of two major subtypes, that is, intragenic (intronic) and intergenic, with most showing clustering with a common promotor. The major mechanism of gene regulation is at the posttranslational level, by binding to the corresponding miRNAs, typically resulting in repression. The entire process can be summed up as miRNAs are transcribed by RNA polymerase II, which creates a pri-miRNA, which is converted to pre-miRNA and finally exported as miRNA into the cytoplasm. This final miRNA forms a complex called RNAinduced silencing complex, which leads to binding and inhibition of target miRNAs. ${ }^{26}$ Deregulation of miRNA function, both through genomic and epigenomic mechanisms, is increasingly seen to occur in several malignancies, including myeloma. In MM, deregulation of miRNA function can be noted at all disease stages, from MGUS to MM. Multiple studies have demonstrated deranged miRNA function in PCs from MGUS and MM cells compared with normal PCs. ${ }^{27}$ Remarkably, the changes seen in a particular miRNA are seen to proceed in the same trend with disease progression, raising the possibility that specific changes have a part to play in pathogenesis and disease progression. ${ }^{28}$

\section{Histone Modification in Myeloma Is a Complex Multistep Process}

Histone proteins are subject to several covalent posttranslational modifications, of which over 15 have been described in detail. ${ }^{10}$ Histone modification is reversible, and the processes involved have effector and eraser functions with a set of reciprocally active enzymes. Acetylation, phosphorylation, and methylation are the most well described, with the first two being clear markers of active transcription ${ }^{29}$ Methylation, on the other hand, is more complex, as the final effects of methylation depend on the amino acids modified and the degree of methylation (mono, di, or tri). ${ }^{30}$ Histone methylation is seen to occur at basic amino acids, namely arginine, histidine, and lysine, and may have a variable effect on transcription depending on context (i.e., type and site of amino acid that is methylated). ${ }^{31}$ A common nomenclature is used to define histone modifications, comprising the name of histone protein (e.g., H2), abbreviation and position of amino acid (K or M), chemical group added (e.g., methyl = Me or Acetyl = Ac), and copies of the modifier added $(1,2$, or 3$)$. Therefore, addition of a dimethyl group to a lysine residue in position 36 on histone protein $\mathrm{H} 3$ is abbreviated as H3K36Me2. This process is summarized in - Fig. 3.

\section{Histone Dimethylation}

Histone dimethylation is catalyzed by enzymes containing the SET domain with methyltransferase activity. In this wellcharacterized group, mutations in MMSET, NSD1, and NSD2 are found in several patients at diagnosis and relapse. MMSET is one of the most well defined, and catalyzes the addition of H3K36me2, associated with active transcription. ${ }^{32}$ It is seen to be associated with the $t(4 ; 14)$ translocation, leading to transcriptional activation and is associated with a poorer outcome in patients with MM. ${ }^{33}$ Over the past decade, there has been an increasing recognition of the biological contribution of MMSET to pathogenesis of myeloma. MMSET is shown to activate the MAF gene through the MAP kinase pathway, indicating indirect activation of an oncogene. MMSET is also implicated in activation of several downstream mitogenic pathways, including c-myc and IRF4. ${ }^{34}$

\section{Histone Trimethylation}

Histone trimethylation is brought about by enzymatic units of enhancer of Zeste homologue 2 (EZH1/2) complexes, which deposit H3K27me3 on target genes. EZH2 is part of

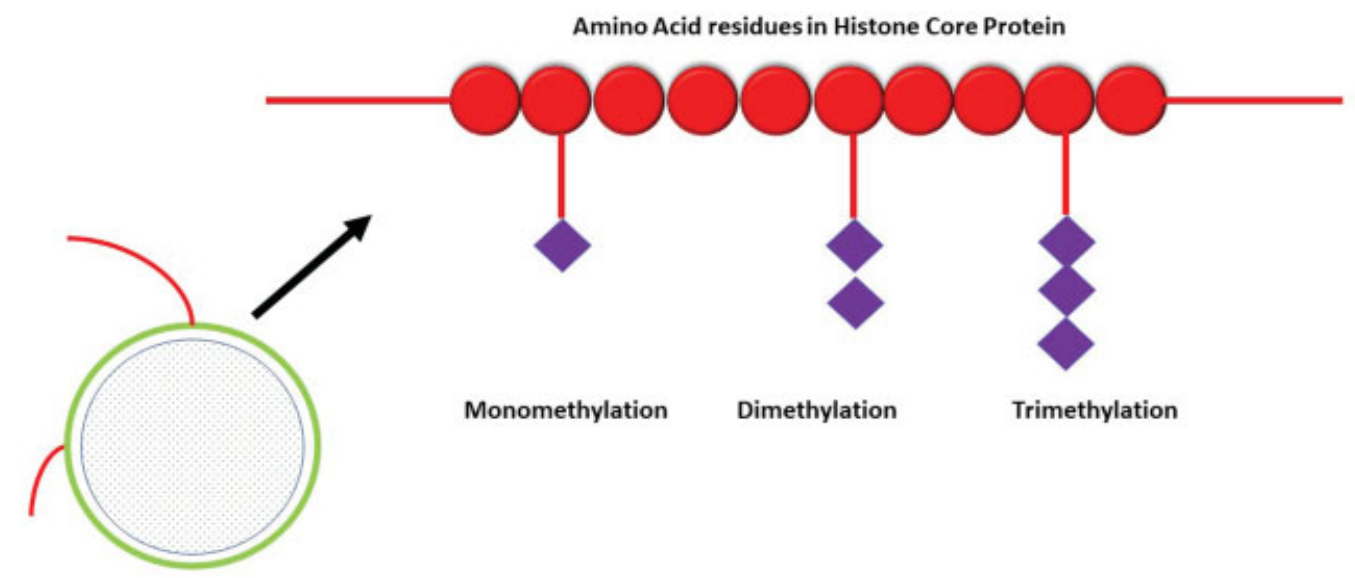

Histone protein with tightly wound chromatin (green) and histone tails (red)

Methyl Residue added to specific amino acids on the histone tails

Fig. 3 Patterns of histone methylation. Methylation occurs on specific amino acids in the histone core protein and is mediated by histone methyl transferases. Depending on the number of methyl groups added, it can either occur as mono-, di-, or trimethylation. 
the polycomb repressor complex (PRC), which silences several downstream genes. The role of EZH2 varies in different malignancies, and in MM it is shown to be upregulated and correlates with a poor outcome. ${ }^{35}$ Similar to MMSET, EZH2 overexpression induces disease progression through a variety of mechanisms. EZH2 is shown to induce proliferation of MM cells independent of interleukin 6 (IL-6). It is also shown to control the expression of tumor suppressor miRNAs that target c-myc, BLIMP-1, and IRF4. ${ }^{36}$

\section{Histone Monomethylation}

Histone monomethylation at lysine sites deposits H3K9me and is essential for gene repression at promoter regions. H3K9 transferring enzymes are elevated in MM patients. KDM3A leads to IRF4 supported cell growth in MM. ${ }^{37}$

\section{Histone Acetylation}

Histone acetylation is seen to occur at lysine residues, which opens up chromatin and makes it transcriptionally active. This process is reversibly regulated by lysine transferases (KATs) and deacetylases (histone deacetylase inhibitors [HDACs] $){ }^{38}$ Mutated KAT genes are found in several patients with MM, especially at relapse, possibly loss of function mutations. HDACs are overexpressed in myeloma and are associated with poor prognosis. ${ }^{39}$

\section{Role of Epigenetic Mechanisms in Disease Progression and Drug Resistance}

Epigenetic processes have been found to play a significant role in two important processes mediating disease progression, that is, PC plasticity and drug resistance.

Analysis of malignant PCs in myeloma reveals a heterogeneous population comprising PCs (CD138+/CD19-), preplasma cells (pre-PCs: CD19-/CD138-), and plasmablasts (CD19+). A vast majority of the cells are CD19-/CD138+ and predominant mediators of disease phenotype, including immunoglobulin secretion and organ damage. A clone of prePCs with a CD19-/CD138- represents a small minority, representing a quiescent population. This clone confers resistance to therapy and is in dynamic equilibrium with CD138+ PCs. ${ }^{40}$

Several characteristics of this process indicate a significant role played by epigenetic processes. Pre-PC populations demonstrate high concentrations of several epigenetic regulators, including PRC, MLL transcriptional activating complex, demethylases, HDACS and $\mathrm{KDM} 5 \mathrm{C} / \mathrm{D}$, indicating epigenetic control. Additionally, the absence of irreversible genetic mutations or change in CD138 miRNA levels makes genetic level (transcriptional/ translational) control unlikely. ${ }^{41}$ These cells are intrinsically resistant to proteasome inhibitors, and may indicate a reservoir that can proliferate at relapse.

Additionally, epigenetic mechanisms are observed to mediate many aspects of drug resistance in patients with myeloma. Epigenetic inactivation of RASD1 is essential in mediating glucocorticoid resistance. Several miRNAs have been found to mediate drug resistance through diverse mechanisms, including modulation of target genes, upregu- lation of oncogenes, and modification of drug efflux mechanisms. A review by Rastgoo et al provides a succinct overview of drug resistance mediated by miRNA. ${ }^{42}$ The control of cell adhesion-mediated drug resistance by altering microenvironment interactions and modification of antiapoptotic signals also have significant epigenetic control. The description of all allied mechanisms is out of scope of this review and is summarized elegantly by Furukawa et al. ${ }^{43}$

\section{Therapeutic Applications of Epigenetic Modifications in Myeloma}

All the mechanisms described above provide potential therapeutic targets. The following discussion summarizes salient features of some of the commonly described mechanisms. Many mechanisms have been translated to clinical applications, and a summary of recent or ongoing trials utilizing the same is provided in - Table 1.

\section{Promotor Region Hypermethylation Is a Potential Therapeutic Target}

Promoter region hypermethylation of several tumor suppressor genes has been documented in myeloma (summarized in -Table 2). The use of hypomethylating agents, azacytidine (Aza) and decitabine, thus has a potential role in reversing this phenomenon. ${ }^{44}$ The in vitro efficacy of Aza against MM cell lines was demonstrated in 2008, where it was shown that Aza led to demethylation of p16, theoretically restoring its tumor suppressor function. It also inhibited IL-6 production and expression of IL- 6 receptor, leading to apoptosis of MM cell lines. ${ }^{45}$ Further, Aza has been shown to have synergistic activity with several other chemotherapeutic agents in MM. Bortezomib and doxorubicin have been shown to sensitize PCs in MM to the effects of Aza by synergistic induction of double strand DNA breaks. ${ }^{46}$ Thus, Aza, possibly in combination with other commonly used chemotherapeutic agents, may have a potential therapeutic role in MM.

\section{Preclinical Efficacy of Targeting miRNA Mechanisms}

Several miRNAs have been shown to have therapeutic efficacy against PCs from MM cells in preclinical studies. MiR$29 \mathrm{~b}$ is shown to have anti-MM activity through multiple mechanisms, including inhibition of IL-6 and JAK STAT signaling. ${ }^{47}$ It has been shown to inhibit MM cell growth in vitro and potentiates the antitumor efficacy of bortezomib. ${ }^{48}$ Many miRNAs have been found to have tumor suppressor functions. For instance, miR-192, -194, and -215 upregulate P53 expression, and their downregulation is involved in disease progression. ${ }^{49}$ Similarly, miR-34 is also shown to mediate similar activity by controlling cell proliferation and differentiation. Synthetic miR-34 constructs were found to have significant anti-MM activity, and found to potentiate the same in combination with other anti-MM agents. ${ }^{50}$ AntiMM cell activity is also noted with miR-15a and 16a through multiple mechanisms, including inhibition of BCL2, IL-17, and angiogenesis (via vascular endothelial growth factor). Downregulation of antitumor activity is observed to correlate with advanced disease stages. ${ }^{51}$ 
Table 1 A snapshot of currently ongoing clinical trials utilizing epigenetic pathways for treatment of myeloma, predominantly in the relapsed/refractory setting

\begin{tabular}{|c|c|c|c|}
\hline $\begin{array}{l}\text { Mechanism } \\
\text { targeted }\end{array}$ & $\begin{array}{l}\text { Drug/Preclinical } \\
\text { molecule }\end{array}$ & Trial phase and design & Salient findings \\
\hline \multirow[t]{2}{*}{ DNMT } & Oral azacytidine ${ }^{86}$ & $\begin{array}{l}\text { Oral azacytidine in combina- } \\
\text { tion with Len/Dex for RRMM }\end{array}$ & $\begin{array}{l}\text { ORR was } 37.5 \% \text {; clinical benefit rate was } 50 \% \text {. Me- } \\
\text { dian OS was } 10.3 \text { mo; median PFS was } 2.6 \text { mo }\end{array}$ \\
\hline & Injectable azacytidine ${ }^{87}$ & $\begin{array}{l}\text { Phase } 1 \mathrm{~b} \text {, twice a week } \mathrm{S} / \mathrm{C} \\
\text { azacytidine with Len/Dex for } \\
\text { RRMM }\end{array}$ & $\begin{array}{l}\text { The median PFS was } 3.1 \mathrm{mo}(95 \% \mathrm{Cl}: 2.1-5.1 \mathrm{mo}) \text {, } \\
\text { median TTP } 2.7 \text { mo ( } 95 \% \mathrm{Cl}: 2.1-7.5 \mathrm{mo}) \text {, and } \\
\text { median OS } 18.6 \mathrm{mo}(95 \% \mathrm{Cl}: 12.9-33.0 \mathrm{mo})\end{array}$ \\
\hline \multirow[t]{6}{*}{ HDAC } & Panobinostat $^{53}$ & $\begin{array}{l}\text { Phase } 3 \text {, panobinostat + Vd vs. } \\
\text { Vd alone for RRMM }\end{array}$ & $\begin{array}{l}\text { PFS advantage, } 11.99 \text { mo }(95 \% \mathrm{Cl}: 10 \cdot 33-12.94) \text { vs } \\
8.08 \text { mo (7.56-9.23); HR 0.63, } 95 \% \mathrm{Cl} 0.52-0.76 ; p \\
<0.0001 \text {. OS difference not yet clear }\end{array}$ \\
\hline & Tefinostat $^{88}$ & $\begin{array}{l}\text { Phase } 1 \text {, dose escalation trial } \\
\text { of oral drug }\end{array}$ & $\begin{array}{l}\text { Safety and maximal tolerated dose defined. Further } \\
\text { clinical studies planned }\end{array}$ \\
\hline & Romidepsin $^{89}$ & $\begin{array}{l}\text { Phase } 2 \text { trial in thirteen } \\
\text { patients }\end{array}$ & $\begin{array}{l}\text { Initial safety and clinical improvement noted, Phase } \\
3 \text { trials planned }\end{array}$ \\
\hline & & $\begin{array}{l}\text { Phase } 1 / 2 \text { trial in combination } \\
\text { with Len for refractory disease }\end{array}$ & $\begin{array}{l}\text { Active, completed recruitment December } 2020 . \\
\text { Updates available at NCT01755975 }\end{array}$ \\
\hline & Vorinostat $^{90}$ & $\begin{array}{l}\text { Bortezomib alone or with } \\
\text { Vorinostat in patients with } \\
\text { RRMM }\end{array}$ & $\begin{array}{l}\text { Median PFS was } 7.63 \text { mo }(95 \% \mathrm{Cl}: 6 \cdot 87-8 \cdot 40) \text { in the } \\
\text { Vorinostat group and } 6 \cdot 83 \mathrm{mo}(5 \cdot 67-7 \cdot 73) \text { in the } \\
\text { placebo group (HR } 0 \cdot 77,95 \% \mathrm{Cl}: 0.64-0.94 ; p= \\
0.0100 \text {. OS difference not yet clear }\end{array}$ \\
\hline & Ricolinostat $^{91}$ & $\begin{array}{l}\text { Phase } 1 / 2 \text { trial of ricolinostat } \\
\text { + bortezomib/DeX }\end{array}$ & ORR $37 \%$, responses in bortezomib refractory $14 \%$ \\
\hline \multirow[t]{4}{*}{ BET } & $\mathrm{CPI} 203^{92}$ & In vitro & $\begin{array}{l}\text { Increased myeloma cell kill in vitro when added to } \\
\text { Len/Dex combination }\end{array}$ \\
\hline & Molibresib $^{93}$ & Phase 1 & $\begin{array}{l}\text { Trial including patients with multiple hematological } \\
\text { and solid organ cancers. Safety and tolerability } \\
\text { established }\end{array}$ \\
\hline & CPI-0160 & Phase 1 & $\begin{array}{l}\text { Recruitment completed; results awaited. Details at } \\
\text { NCT02157636 }\end{array}$ \\
\hline & R06870810 94 & Phase 1 & $\begin{array}{l}\text { Safety established Partial responses in } 16 \% \text {, includ- } \\
\text { ing daratumumab resistant patients. }\end{array}$ \\
\hline \multirow[t]{2}{*}{$\mathrm{EZH}$} & EPZ $6438^{95}$ & In vitro & $\begin{array}{l}\text { EPZ6438 in combination with Len represses myc and } \\
\text { activates tumor suppressor genes }\end{array}$ \\
\hline & Tazemetostat & Phase 1 & $\begin{array}{l}\text { Currently recruiting for solid tumors and } \\
\text { lymphomas }\end{array}$ \\
\hline
\end{tabular}

Abbreviations: $\mathrm{Cl}$, confidence interval; Dex, dexamethasone; DNMT, DNA methyl transferases; EZH, enhancer of Zeste homologue; HDAC, histone deacetylase inhibitor; HR, hazard ratio; Len, lenalidomide; ORR, overall response rate; OS, overall survival; PFS, progression-free survival; RRMM, relapsed/refractory multiple myeloma; Vd, bortezomib-dexamethasone.

Table 2 Summary of pathologic genes hypermethylated in multiple myeloma

\begin{tabular}{|l|l|l|l|}
\hline Name & Normal function & Frequency & Comments \\
\hline P16 & Inhibits CDK 4 and 6 & $19-53 \%$ & $\begin{array}{l}\text { Associated with poor outcomes } \\
\text { Involved in progression from MGUS to myeloma }\end{array}$ \\
\hline SHP and SOCS ${ }^{83}$ & $\begin{array}{l}\text { Inhibition of JAK/STAT } \\
\text { function }\end{array}$ & $20-79 \%$ & Overactivity of IL-6 stimulated JAK/STAT \\
\hline E-Cadherin & $\begin{array}{l}\text { Cell adhesion inhibits } \\
\text { cellular mobility }\end{array}$ & $27-56 \%$ & $\begin{array}{l}\text { Disease progression marker for high-risk disease, } \\
\text { immature morphology }\end{array}$ \\
\hline DAPK & Proapoptotic kinase & $12.5-67 \%$ & Associated with high-risk disease, poorer response to therapy \\
\hline $\begin{array}{l}\text { DNA damage } \\
\text { repair genes }\end{array}$ & Multiple genes & & More information needed for exact function \\
\hline
\end{tabular}

Abbreviation: IL-6, interleukin 6; MGUS, monoclonal gammopathy of undetermined significance.

Source: Adapted from Sharma et al. ${ }^{84}$ 


\section{Histone Modification Has Potential Therapeutic Applications}

As there are multiple pathways leading to histone modification in MM, several potential therapeutic approaches exist to exploit these pathways for antimyeloma efficacy. Out of the various drugs studied, HDACs are some of the most well characterized with a proven clinical efficacy. ${ }^{52}$ Panobinostat is a nonselective HDAC inhibitor that has been approved for the treatment of relapsed/refractory myeloma based on phase 3 data. ${ }^{53}$ Two important features noted with the use of HDAC inhibitors. First, a high rate of cardiac adverse events and cytopenia is noted, indicating several off target epigenetic effects that are still to be elucidated. The use of more selective HDAC inhibitors is expected to reduce these serious adverse events. Second, the efficacy of these drugs, even the newer selective HDAC inhibitors, is only modest as single agents. The best results are seen in combination with other anti-MM agents. ${ }^{54}$ Several clinical scores based on gene expression profile to predict response to HDAC inhibitors have been described. ${ }^{55}$ Histone acetylation is always activating, but histone methylation may be activating or deactivating. Several small molecule modifiers of histone methylation are still in preclinical or phase 1 trials (NCT02082977). ${ }^{56}$

\section{Mediators of Histone Methylation Are Forthcoming Therapeutic Targets}

Histone proteins are found in the nucleus of all eukaryotic cells and exist as octamers, around which double-stranded DNA is wrapped. Each cell has two copies of each of the histone proteins $\mathrm{H} 2 \mathrm{~A}, \mathrm{H} 2 \mathrm{~B}, \mathrm{H} 3$, and $\mathrm{H} 4$ that form nucleosomes around which DNA is compactly packed. Release of DNA from histone proteins leads to chromatin modification and activation of transcription, which is otherwise suppressed. ${ }^{57}$ Histone modifications act by influencing the recruitment of nonhistone proteins and the levels of chromatin compaction, altering the accessibility of transcription factors to DNA. Posttranslational modification of histone proteins is an essential biologic process, required for normal development and cellular functioning. ${ }^{58}$ The most important and clinically relevant mechanisms of histone modification consist of acetylation and methylation. We will focus on histone methylation for this discussion, which is amenable to therapeutic intervention in myeloma.

\section{Histone Methylation}

Histone methylation occurs on basic amino acids, that is, arginine, lysine, and histidine, and varies according to the amino acid in question. Lysine can be mono-, di-, or trimethylated, arginine mono- or demethylated, and histidine monomethylated. Histone methylation is context dependent, and effects on genetic expression may vary based on the location of the target residue and degree of methylation. ${ }^{58}$ An extensive review by Greer and Shi summarizes histone modification in detail, and a relevant summary of these changes is provided below. ${ }^{58}$

Enzymes mediating histone changes are thought to be attracted to DNA through specific sequences, the most prominent being the polycomb repressor group. The meth- ylation status of histones is read by proteins with methyl binding domains. Many mechanisms are thought to be in play, but most elegantly, the positive charge created by methyl residues is thought to increase the binding of hydrophobic proteins. ${ }^{59}$ Histone methylation is mediated by a group of enzymes called histone methyltransferases, of which arginine and lysine methyltransferases are the most relevant.

Arginine methyltransferases comprise nine members in all, as a part of the protein arginine methyltransferase family (PRMT), which mediate methylation of arginine. ${ }^{60}$ These enzymes catalyze two types of dimethylation and one monomethylation. Monomethylation is regarded as an intermediate metabolite in the formation of di-ch3-arginine. PRMTs are constitutively active and involved in cell growth and development, and multiple mechanisms exist for regulation of activity of PRMTs. PTM, including methylation and phosphorylation, inhibit PRMT function. In addition, PTM already on the substrate prevents further addition of methyl groups. For example, phosphorylation blocks methylation and acetylation stimulates methylation. ${ }^{61}$ Expression of PRMTs has been altered in several malignancies.

Lysine methyltransferases are part of a more extensive family and are characterized by the presence of a catalytic SET domain, which is conserved across all members of the family. The SET domain, named after drosophila proteins from which it was isolated, executes the final catalytic activity of these enzymes. ${ }^{62}$ SET containing proteins can be further subclassified based on sequence homology around the catalytic domain. Six families, namely, SUV39, EZH, SET2, PRDM, SMYD5, and KMT4 (an exception with no SET domain), have been identified. Interestingly, SET containing proteins also have the property of being able to read PTMs, indicating a linkage of reader and writer functions in mediating overall control of histone modification. ${ }^{63}$

Salient details about the clinically important members from both of the above two groups are listed below, which also form the focus of our study. - Table 3 summarizes important enzymes involved in histone methylation.

MMSET: MMSET catalyzes the addition of H3K36me2, which is associated with active chromatin. The significance of MMSET activation is seen in myeloma with $\mathrm{t}(4 ; 14)$ translocation, which shows universal activation of this gene. ${ }^{64}$ MMSET expression has been found to promote myeloma tumor growth in vitro, with MMSET knockdown leading to growth arrest. ${ }^{65}$ MMSET also indirectly activates the activation of several oncogenic proteins that act as transcription activators and play a role in carcinogenesis, including IRF4, MAF, and c-MYC. Recently, it has also been shown to induce degradation of $\mathrm{p} 53$, thus increasing cellular proliferation. ${ }^{66}$ MMSET also enhances the ability of malignant PCs to repair DNA damage, leading to resistance to alkylating agent-based chemotherapy. $^{67}$

EZH2: EZH2 catalyzes the addition of a trimethyl mark H3K27me3, which is associated with repression of gene expression. EZH2 is part of a PRC, which contains EZH2, ASXL1, EED, and other accessory proteins. ${ }^{68}$ EZH2 overexpression has been found to be associated with dysregulation 
Table 3 A summary of enzymes involved in histone methylation and their therapeutic correlates

\begin{tabular}{|l|l|l|l|l|l|}
\hline $\begin{array}{l}\text { Methylation } \\
\text { modifier }\end{array}$ & Prooncogenic effect & Others & Drug resistance & $\begin{array}{l}\text { Adverse } \\
\text { effect on } \\
\text { survival }\end{array}$ & $\begin{array}{l}\text { Preclinical small } \\
\text { molecule inhibitor }\end{array}$ \\
\hline MMSET & $\downarrow$ P53 function & $\uparrow$ IRF-4, MAP, c-MYC & $\begin{array}{l}\text { By resistance to } \\
\text { DS-DNA breaks }\end{array}$ & Yes & No \\
\hline EZH2 & $\begin{array}{l}\downarrow \text { TS miRNA, } \downarrow \text { TS Genes } \\
\text { (CDKN1C, RBPMS, LTB) }\end{array}$ & $\begin{array}{l}\uparrow \text { Oncogenes, c-Myc, } \\
\text { UUNB, BLIMP1 }\end{array}$ & $\begin{array}{l}\text { By cell adhesion } \\
\text { mediated drug } \\
\text { resistance }\end{array}$ & Yes & $\begin{array}{l}\text { Yes, E7438, } \\
\text { UNC1999 and GSK } \\
126\end{array}$ \\
\hline PRMT5 & $\uparrow$ NF-kB pathway & $\downarrow$ IKK 3 & No & Yes & Yes, EPZ015666 \\
\hline KDM1A & $\downarrow$ p53 & $\uparrow$-MYC & No & $\begin{array}{l}\text { Yranylcypromine, } \\
\text { GSK-LSD1, and ORY- } \\
1001\end{array}$ \\
\hline KDM3A & $\uparrow$ KLF2, IRF4, MALAT1 & $\downarrow$ Apoptosis & No & Yes & No \\
\hline KDM6A & $\begin{array}{l}\downarrow \text { Tumor Suppressor } \\
\text { function (self) }\end{array}$ & Coordinates with EZH2 & No & $\begin{array}{l}\text { Sensitizes to EZH2 } \\
\text { inhibition }\end{array}$ \\
\hline KDM6B & $\uparrow$ ELK, FOS, MAP-k & - & No & Yes & - \\
\hline
\end{tabular}

Source: Adapted Adapted from Sharma et $\mathrm{al}^{84}$ and Anderson et al ${ }^{85}$

of cell cycle control and overall inferior outcomes. The effects of EZH2 overexpression are context dependent, and lead to activation of transcription in DLBCL/Follicular lymphoma and silencing in myeloma. ${ }^{69}$ Multiple downstream effects of EZH2 include suppression of tumor suppressor miRNAs and upregulation of antiapoptotic and pro-oncogenes. ${ }^{70}$ EZH2 also leads to poorer outcomes by repression of p21 and p15 via H3K27me3, leading to uncontrolled cyclin D overexpression and cellular proliferation. ${ }^{35}$
PRMT5: PRMT5 is an arginine methyltransferase and catalyzes dimethylation of arginine. PRMT5 is overexpressed in myeloma and is associated with inferior outcomes. It activates multiple oncogenic pathways, most notably the nuclear factor-kappa B pathway. ${ }^{71}$ Pharmacologic inhibition of PRMT5 is a potential therapeutic target.

Demethylases: Histone demethylases consist of a large group of enzymes, of which important members are listed below.

Table 4 A summary of studies describing the prognostic impact of epigenetic modifications in myeloma

\begin{tabular}{|c|c|c|c|}
\hline Study & Parameters & Specific genes & Salient findings \\
\hline \multirow[t]{4}{*}{ Kaiser et al ${ }^{96}$} & $\begin{array}{l}\text { Global methylation status of } \\
\text { tumor suppressor genes in } \\
\text { myeloma }\end{array}$ & GPX3 & $\begin{array}{l}\text { Median OS high vs. low meth- } \\
\text { ylation status, } 16 \text { vs. } 46 \mathrm{mo}, p \\
=0.0001\end{array}$ \\
\hline & & RBP1 & 23.9 vs. $47.7 \mathrm{mo}, p<0.0001$ \\
\hline & & SPARC & 19.4 vs. $47.7 \mathrm{mo}, p<0.0001$ \\
\hline & & TGFB1 & 25.7 vs. $50.9 \mathrm{mo}, p<0.0001$ \\
\hline Barwick et al ${ }^{97}$ & Global DNA methylome & & $\begin{array}{l}\text { Low vs. high methylation sta- } \\
\text { tus, median OS: } 2 \text { y vs. not } \\
\text { reached, } p=8.7 \mathrm{e}-8\end{array}$ \\
\hline \multirow[t]{2}{*}{ Mithraprabhu et al ${ }^{39}$} & $\begin{array}{l}\text { Histone deacetylase } \\
\text { expression }\end{array}$ & $\begin{array}{l}\text { Class I HDACs, HDAC 1,2,3, } \\
\text { and } 8 \text { and Class II HDACs, } \\
\text { HDAC5 and } 10\end{array}$ & $\begin{array}{l}\text { High vs. low expression } \\
\text { shorter PFS }(p=0.07) \text { and OS } \\
(p=0.003)\end{array}$ \\
\hline & & KDM6A mutation & $\begin{array}{l}\text { Mutated vs. wild-type PFS: } \\
16.8 \text { vs } 26.6 \text { mo; proportion } \\
\text { alive at } 2 \text { y mutated vs. wild } \\
\text { type: } 51 \text { vs. } 80 \%\end{array}$ \\
\hline Pawlyn et a ${ }^{98}$ & & DNA methylation modifier & $\begin{array}{l}\text { Mutated vs. wild-type PFS: NR } \\
\text { vs. } 26.6 \text { mo; percent alive at } 2 \\
\text { y mutated vs. wild-type: } 58 \text { vs. } \\
80 \%\end{array}$ \\
\hline
\end{tabular}

Abbreviations: HDAC, histone deacetylase inhibitor; OS, overall survival; PFS, progression-free survival. 
KDM1A: KDM1A (also known as LSD1), demethylates H3K4. It coordinates with several other cellular proteins, including MMSET and HDAC. KDM1A has several nonhistone targets, notably p53, whose function it inhibits, and has been associated with a poorer prognosis for multiple malignancies. $^{72}$ In myeloma, inhibition of KDM1A has been found to inhibit interaction with epithelium and osteoclastogenesis. It has also been associated with activation of multiple pathways, including the c-myc pathway that contributes to pathogenesis and inferior overall survival. ${ }^{73}$

KDM3 family: It consists of KDM3A, KDM3B, and JMJD1C. It has been found to be associated with MM cell survival as part of the KDM3A-KLF2-IRF4 axis, and levels are seen to be increased in MM patients compared with controls. ${ }^{37}$ It has been shown that hypoxia inducible KDM3A knocks out KDM3A induced apoptosis and leads to an antiapoptotic phenotype in malignant MM cells. $^{74}$

KDM6A: Also known as UTX. It removes H3K27me2 and me3, methyl marks correlated with genomic silencing. KDM6A mutations have been implicated in several malignancies, including ALL/CMML and bladder cancers. ${ }^{75}$ KDM6A mutations have been noted in over $10 \%$ of patients with MM and have been associated with a poorer prognosis. UTX loss is associated with increased proliferation and clonogenicity of MM cells. ${ }^{76}$ Closely related KDM6B is also noted to play a role in MM cell survival and leads to activation of MAP-K pathway genes. $^{77}$

\section{Clinical Analysis of Epigenetic Modifications}

Changes in epigenetic modifications, including methylation and acetylation status, can be quantitatively measured and have been shown to have several prognostic implications. A basic understanding of clinical evaluation of epigenetic modifications is essential to appraise studies describing epigenetic pathways. DNA methylation has been traditionally tested with bisulfite sequencing, in which bisulfite is used to convert unmethylated cytosine to uracil, differentiating it from methylated cytosine. Recently, CpG island microarray has been utilized to provide a high throughput method for methylation status. ${ }^{78}$ Histone modification is traditionally measured by CHiP sequencing, which can detect any protein as long as a specific antibody is available. ${ }^{79}$ This has been upscaled with combination with chip microarray. ${ }^{80}$ There is no single standard method of choice for miRNA analysis, and a comparative analysis can be found in this excellent review. ${ }^{81}$ An overview of studies indicating prognostic impact of epigenetic changes at diagnosis is summarized in - Table 4 .

\section{Conclusions}

Epigenetic pathways are being observed to play an increasingly important role in pathogenesis and disease progression in myeloma and have a significant prognostic impact. There are two critically important clinical correlates of the above advances in basic science. First, these pathways provide a new approach to therapeutic intervention in $\mathrm{MM}$, and can be targeted by multiple approaches. Considering the incurable nature of disease and paradigm for continuous therapy, identifying a newer therapeutic approach is an important step forward. Second, epigenetic mechanisms can explain geographic and ethnic differences in disease phenotype and outcomes not explained by conventional cytogenetics, improving our understanding of disease biology. The current review provides a short overview of the above, with clinical correlates, and will be a useful primer for better understanding of this intriguing approach.

Conflict of Interest

None declared.

\section{References}

1 Biswas S, Rao CM. Epigenetics in cancer: fundamentals and beyond. Pharmacol Ther 2017;173:118-134

2 Sharma S, Kelly TK, Jones PA. Epigenetics in cancer. Carcinogenesis 2010;31(01):27-36

3 Feinberg AP, Ohlsson R, Henikoff S. The epigenetic progenitor origin of human cancer. Nat Rev Genet 2006;7(01):21-33

4 Ravi P, Kumar SK, Cerhan JR, et al. Defining cure in multiple myeloma: a comparative study of outcomes of young individuals with myeloma and curable hematologic malignancies. Blood Cancer J 2018;8(03):26

5 Kumar SK, Rajkumar SV, Dispenzieri A, et al. Improved survival in multiple myeloma and the impact of novel therapies. Blood 2008; 111(05):2516-2520

6 Rajkumar SV. Value and cost of myeloma therapy. Am Soc Clin Oncol Educ Book 2018;38(38):662-666

7 Gupta P, Kochupillai V, Singh S, Berry M, Kumar L, Sundaram K. A twelve year study of multiple myeloma at the All India Institute of Medical Sciences, New Delhi, India. Indian J Med Paediatr Oncol 1995; 16(02):108

8 Wang Y, Leung FC. An evaluation of new criteria for CpG islands in the human genome as gene markers. Bioinformatics 2004;20(07): 1170-1177

9 Allfrey VG, Faulkner R, Mirsky AE. Acetylation and methylation of histones and their possible role in the regulation of RNA synthesis. Proc Natl Acad Sci U S A 1964;51(05):786-794

10 Kouzarides T. Chromatin modifications and their function. Cell 2007;128(04):693-705

11 Mattick JS, Makunin IV. Non-coding RNA. Hum Mol Genet 2006; 15(Suppl 1):R17-R29

12 Rajkumar SV, Gupta V, Fonseca R, et al. Impact of primary molecular cytogenetic abnormalities and risk of progression in smoldering multiple myeloma. Leukemia 2013;27(08):1738-1744

13 Kumar S, Fonseca R, Ketterling RP, et al. Trisomies in multiple myeloma: impact on survival in patients with high-risk cytogenetics. Blood 2012;119(09):2100-2105

14 Abdallah N, Rajkumar SV, Greipp P, et al. Cytogenetic abnormalities in multiple myeloma: association with disease characteristics and treatment response. Blood Cancer J 2020;10(08):82

15 Kumar SK, Rajkumar SV. The multiple myelomas - current concepts in cytogenetic classification and therapy. Nat Rev Clin Oncol 2018;15(07):409-421

16 San-Miguel JF, Paiva B, Gutiérrez NC. New tools for diagnosis and monitoring of multiple myeloma. Am Soc Clin Oncol Educ Book 2013

17 Galm O, Wilop S, Reichelt J, et al. DNA methylation changes in multiple myeloma. Leukemia 2004;18(10):1687-1692

18 Agirre X, Castellano G, Pascual M, et al. Whole-epigenome analysis in multiple myeloma reveals DNA hypermethylation of B cellspecific enhancers. Genome Res 2015;25(04):478-487

19 Liang G, Weisenberger DJJE. DNA methylation aberrancies as a guide for surveillance and treatment of human cancers. Epigenetics 2017; 12(06):416-432 
20 Schulz WA, Elo JP, Florl AR, et al. Genome-wide DNA hypomethylation is associated with alterations on chromosome 8 in prostate carcinoma. Genes Chromosomes Cancer 2002;35(01):58-65

21 Bollati V, Fabris S, Pegoraro V, et al. Differential repetitive DNA methylation in multiple myeloma molecular subgroups. Carcinogenesis 2009;30(08):1330-1335

22 Heuck CJ, Mehta J, Bhagat T, et al. Myeloma is characterized by stage-specific alterations in DNA methylation that occur early during myelomagenesis. J Immunol 2013;190(06):2966-2975

23 Latalova P, Minarik J, Smesny Trtkova K. De novo methyltransferases, DNMT3a and DNMT3b are underexpressed in multiple myeloma. Blood 2015;126(23):4818

24 Auclair G, Weber M. Mechanisms of DNA methylation and demethylation in mammals. Biochimie 2012;94(11):2202-2211

25 Lee RC, Feinbaum RL, Ambros V. The C. elegans heterochronic gene lin-4 encodes small RNAs with antisense complementarity to lin-14. Cell 1993;75(05):843-854

26 Krol J, Loedige I, Filipowicz W. The widespread regulation of microRNA biogenesis, function and decay. Nat Rev Genet 2010;11 (09):597-610

27 Zhou Y, Chen L, Barlogie B, et al. High-risk myeloma is associated with global elevation of miRNAs and overexpression of EIF2C2/ AGO2. Proc Natl Acad Sci U S A 2010;107(17):7904-7909

28 Lionetti M, Biasiolo M, Agnelli L, et al. Identification of microRNA expression patterns and definition of a microRNA/mRNA regulatory network in distinct molecular groups of multiple myeloma. Blood 2009;114(25):e20-e26

29 Rossetto D, Avvakumov N, Côté J Histone phosphorylation: a chromatin modification involved in diverse nuclear events. Epigenetics 2012;7(10):1098-1108

30 Li B, Carey M, Workman JL. The role of chromatin during transcription. Cell 2007;128(04):707-719

31 Young NL, Dimaggio PA, Garcia BA. The significance, development and progress of high-throughput combinatorial histone code analysis. Cell Mol Life Sci 2010;67(23):3983-4000

32 Martinez-Garcia E, Popovic R, Min D-J, et al. The MMSET histone methyl transferase switches global histone methylation and alters gene expression in t $4 ; 14)$ multiple myeloma cells. Blood 2011; 117(01):211-220

33 Keats JJ, Reiman T, Maxwell CA, et al. In multiple myeloma, $t(4 ; 14)$ (p16;q32) is an adverse prognostic factor irrespective of FGFR3 expression. Blood 2003;101(04):1520-1529

34 Xie Z, Bi C, Chooi JY, Chan ZL, Mustafa N, Chng WJ. MMSET regulates expression of IRF4 in $t(4 ; 14)$ myeloma and its silencing potentiates the effect of bortezomib. Leukemia 2015;29(12): 2347-2354

35 Pawlyn C, Bright MD, Buros AF, et al. Overexpression of EZH2 in multiple myeloma is associated with poor prognosis and dysregulation of cell cycle control. Blood Cancer J 2017;7(03):e549

36 Alzrigat M, Párraga AA, Agarwal P, et al. EZH2 inhibition in multiple myeloma downregulates myeloma associated oncogenes and upregulates microRNAs with potential tumor suppressor functions. Oncotarget 2017;8(06):10213-10224

37 Ohguchi H, Hideshima T, Bhasin MK, et al. The KDM3A-KLF2-IRF4 axis maintains myeloma cell survival. Nat Commun 2016; 7:10258

38 Haberland M, Montgomery RL, Olson EN. The many roles of histone deacetylases in development and physiology: implications for disease and therapy. Nat Rev Genet 2009;10(01):32-42

39 Mithraprabhu S, Kalff A, Chow A, Khong T, Spencer A. Dysregulated Class I histone deacetylases are indicators of poor prognosis in multiple myeloma. Epigenetics 2014;9(11):1511-1520

40 Chen BJ, Epstein J. Circulating clonal lymphocytes in myeloma constitute a minor subpopulation of B cells. Blood 1996;87(05): 1972-1976

41 Sharma SV, Lee DY, Li B, et al. A chromatin-mediated reversible drug-tolerant state in cancer cell subpopulations. Cell 2010;141 (01):69-80
42 Rastgoo N, Abdi J, Hou J, Chang H. Role of epigenetics-microRNA axis in drug resistance of multiple myeloma. J Hematol Oncol 2017;10(01):121

43 Furukawa Y, Kikuchi J. Epigenetic mechanisms of cell adhesionmediated drug resistance in multiple myeloma. Int J Hematol 2016;104(03):281-292

44 Fenaux P, Mufti GJ, Hellstrom-Lindberg E, et al. International Vidaza High-Risk MDS Survival Study Group. Efficacy of azacitidine compared with that of conventional care regimens in the treatment of higher-risk myelodysplastic syndromes: a randomised, open-label, phase III study. Lancet Oncol 2009;10(03): 223-232

45 Khong T, Sharkey J, Spencer A. The effect of azacitidine on interleukin-6 signaling and nuclear factor-kappaB activation and its in vitro and in vivo activity against multiple myeloma. Haematologica 2008;93(06):860-869

46 Kiziltepe T, Hideshima T, Catley L, et al. 5-Azacytidine, a DNA methyltransferase inhibitor, induces ATR-mediated DNA doublestrand break responses, apoptosis, and synergistic cytotoxicity with doxorubicin and bortezomib against multiple myeloma cells. Mol Cancer Ther 2007;6(06):1718-1727

47 Amodio N, Leotta M, Bellizzi D, et al. DNA-demethylating and anti-tumor activity of synthetic miR-29b mimics in multiple myeloma. Oncotarget 2012;3(10):1246-1258

48 Amodio N, Di Martino MT, Foresta U, et al. miR-29b sensitizes multiple myeloma cells to bortezomib-induced apoptosis through the activation of a feedback loop with the transcription factor Sp1. Cell Death Dis 2012;3(11):e436

49 Pichiorri F, Suh S-S, Rocci A, et al. Downregulation of p53-inducible microRNAs 192, 194, and 215 impairs the p53/MDM2 autoregulatory loop in multiple myeloma development. Cancer Cell 2010;18(04):367-381

50 Zarone MR, Misso G, Grimaldi A, et al. Evidence of novel miR-34abased therapeutic approaches for multiple myeloma treatment Sci Rep 2017;7(01):17949

51 Li Y, Zhang B, Li W, et al. MiR-15a/16 regulates the growth of myeloma cells, angiogenesis and antitumor immunity by inhibiting Bcl-2, VEGF-A and IL-17 expression in multiple myeloma. Leuk Res 2016;49:73-79

52 Richardson PG, Hungria VT, Yoon SS, et al. Panobinostat plus bortezomib and dexamethasone in previously treated multiple myeloma: outcomes by prior treatment. Blood 2016;127(06): 713-721

53 San-Miguel JF, Hungria VT, Yoon SS, et al. Panobinostat plus bortezomib and dexamethasone versus placebo plus bortezomib and dexamethasone in patients with relapsed or relapsed and refractory multiple myeloma: a multicentre, randomised, doubleblind phase 3 trial. Lancet Oncol 2014;15(11):1195-1206

54 Vesole DH, Bilotti E, Richter JR, et al. Phase I study of carfilzomib, lenalidomide, vorinostat, and dexamethasone in patients with relapsed and/or refractory multiple myeloma. $\mathrm{Br} \mathrm{J}$ Haematol 2015;171(01):52-59

55 Moreaux J, Rème T, Leonard W, et al. Gene expression-based prediction of myeloma cell sensitivity to histone deacetylase inhibitors. Br J Cancer 2013;109(03):676-685

56 Zagni C, Floresta G, Monciino G, Rescifina A. The search for potent small-molecule HDACIs in cancer treatment: a decade after vorinostat. Med Res Rev 2017;37(06):1373-1428

57 Dimopoulos K, Gimsing P, Grønbæk K. The role of epigenetics in the biology of multiple myeloma. Blood Cancer J 2014;4(05):e207

58 Greer EL, Shi Y. Histone methylation: a dynamic mark in health, disease and inheritance. Nat Rev Genet 2012;13(05):343-357

59 Sprangers R, Groves MR, Sinning I, Sattler M. High-resolution Xray and NMR structures of the SMN Tudor domain: conformational variation in the binding site for symmetrically dimethylated arginine residues. J Mol Biol 2003;327(02):507-520

60 Bedford MT, Clarke SG. Protein arginine methylation in mammals: who, what, and why. Mol Cell 2009;33(01):1-13 
61 Yang Y, Bedford MT. Protein arginine methyltransferases and cancer. Nat Rev Cancer 2013;13(01):37-50

62 Völkel P, Angrand P-O. The control of histone lysine methylation in epigenetic regulation. Biochimie 2007;89(01):1-20

63 Ruthenburg AJ, Li H, Patel DJ, Allis CD. Multivalent engagement of chromatin modifications by linked binding modules. Nat Rev Mol Cell Biol 2007;8(12):983-994

64 Mirabella F, Wu P, Wardell CP, et al. MMSET is the key molecular target in $\mathrm{t}(4 ; 14)$ myeloma. Blood Cancer J 2013;3(05):e114

65 Lauring J, Abukhdeir AM, Konishi H, et al. The multiple myeloma associated MMSET gene contributes to cellular adhesion, clonogenic growth, and tumorigenicity. Blood 2008;111(02):856-864

66 Park JW, Chae YC, Kim JY, Oh H, Seo SB. Methylation of Aurora kinase A by MMSET reduces p53 stability and regulates cell proliferation and apoptosis. Oncogene 2018;37(48):6212-6224

67 Jaksic W, Trudel S, Chang H, et al. Clinical outcomes in $\mathrm{t}(4 ; 14)$ multiple myeloma: a chemotherapy-sensitive disease characterized by rapid relapse and alkylating agent resistance. J Clin Oncol 2005;23(28):7069-7073

68 Margueron R, Reinberg D. The polycomb complex PRC2 and its mark in life. Nature 2011;469(7330)343-349

69 Chase A, Cross NC. Aberrations of EZH2 in cancer. Clin Cancer Res 2011;17(09):2613-2618

70 Tremblay-LeMay R, Rastgoo N, Pourabdollah M, Chang H. EZH2 as a therapeutic target for multiple myeloma and other haematological malignancies. Biomark Res 2018;6(01):34

71 Gullà A, Hideshima T, Bianchi G, et al. Protein arginine methyltransferase 5 has prognostic relevance and is a druggable target in multiple myeloma. Leukemia 2018;32(04):996-1002

72 Nicholson TB, Chen T. LSD1 demethylates histone and nonhistone proteins. Epigenetics 2009;4(03):129-132

73 Wei X, Calvo-Vidal MN, Chen S, et al. Germline lysine-specific demethylase 1 (LSD1/KDM1A) mutations confer susceptibility to multiple myeloma. Cancer Res 2018;78(10):2747-2759

74 Ikeda S, Kitadate A, Abe F, Takahashi N, Tagawa H. Hypoxiainducible KDM3A addiction in multiple myeloma. Blood Adv 2018;2(04):323-334

75 van Haaften G, Dalgliesh GL, Davies H, et al. Somatic mutations of the histone H3K27 demethylase gene UTX in human cancer. Nat Genet 2009;41(05):521-523

76 Ezponda T, Dupéré-Richer D, Will CM, et al. UTX/KDM6A loss enhances the malignant phenotype of multiple myeloma and sensitizes cells to EZH2 inhibition. Cell Rep 2017;21(03):628-640

77 Ohguchi H, Harada T, Sagawa M, et al. KDM6B modulates MAPK pathway mediating multiple myeloma cell growth and survival. Leukemia 2017;31(12):2661-2669

78 Gitan RS, Shi H, Chen CM, Yan PS, Huang TH. Methylation-specific oligonucleotide microarray: a new potential for high-throughput methylation analysis. Genome Res 2002;12(01):158-164

79 Zang C, Schones DE, Zeng C, Cui K, Zhao K, Peng W. A clustering approach for identification of enriched domains from histone modification ChIP-Seq data. Bioinformatics 2009;25(15): 1952-1958

80 Cornett EM, Dickson BM, Rothbart SB. Analysis of histone antibody specificity with peptide microarrays. J Vis Exp 2017 (126): 55912

81 Krepelkova I, Mrackova T, Izakova J, et al. Evaluation of miRNA detection methods for the analytical characteristic necessary for clinical utilization. Biotechniques 2019;66(06):277-284

82 Chim C-S, Liang R, Leung M-H, Kwong YL. Aberrant gene methylation implicated in the progression of monoclonal gammopathy of undetermined significance to multiple myeloma. J Clin Pathol 2007;60(01):104-106
83 Chim C-S, Fung T-K, Cheung W-C, Liang R, Kwong Y-LJB. SOCS1 and SHP1 hypermethylation in multiple myeloma: implications for epigenetic activation of the Jak/STAT pathway. Blood 2004;103 (12):4630-4635

84 Sharma A, Heuck CJ, Fazzari MJ, et al. DNA methylation alterations in multiple myeloma as a model for epigenetic changes in cancer. Wiley Interdiscip Rev Syst Biol Med 2010;2(06):654-669

85 Ohguchi H, Hideshima T, Anderson KC. The biological significance of histone modifiers in multiple myeloma: clinical applications. Blood Cancer J 2018;8(09):83

86 Kalff A, Khong T, Mithraprabhu S, et al. Oral azacitidine (CC-486) in combination with lenalidomide and dexamethasone in advanced, lenalidomide-refractory multiple myeloma (ROAR study. Leuk Lymphoma 2019;60(09):2143-2151

87 Khouri J, Faiman BM, Grabowski D, et al. DNA methylation inhibition in myeloma: experience from a phase $1 \mathrm{~b}$ study of low-dose continuous azacitidine in combination with lenalidomide and low-dose dexamethasone in relapsed or refractory multiple myeloma. Semin Hematol 2021;58(01):45-55

88 Ossenkoppele GJ, Lowenberg B, Zachee P, et al. A phase I first-inhuman study with tefinostat - a monocyte/macrophage targeted histone deacetylase inhibitor - in patients with advanced haematological malignancies. Br J Haematol 2013;162(02):191-201

89 Niesvizky R, Ely S, Mark T, et al. Phase 2 trial of the histone deacetylase inhibitor romidepsin for the treatment of refractory multiple myeloma. Cancer 2011;117(02):336-342

90 Dimopoulos M, Siegel DS, Lonial S, et al. Vorinostat or placebo in combination with bortezomib in patients with multiple myeloma (VANTAGE 088): a multicentre, randomised, double-blind study. Lancet Oncol 2013;14(11):1129-1140

91 Vogl DT, Raje N, Jagannath S, et al. Ricolinostat, the first selective histone deacetylase 6 inhibitor, in combination with bortezomib and dexamethasone for relapsed or refractory multiple myeloma. Clin Cancer Res 2017;23(13):3307-3315

92 Díaz T, Rodríguez V, Lozano E, et al. The BET bromodomain inhibitor CPI203 improves lenalidomide and dexamethasone activity in in vitro and in vivo models of multiple myeloma by blockade of Ikaros and MYC signaling. Haematologica 2017;102 (10):1776-1784

93 Piha-Paul SA, Hann CL, French CA, et al. Phase 1 study of Molibresib (GSK525762), a bromodomain and extra-terminal domain protein inhibitor, in NUT carcinoma and other solid tumors. JNCI Cancer Spectr 2019;4(02):pkz093

94 Ramasamy K, Nooka A, Quach H, et al. Open label, multicenter, dose-escalation/ expansion phase Ib study to evaluate safety and activity of BET inhibitor RO6870810 (RO), given as monotherapy to patients (pts) with advanced multiple myeloma. Blood 2020; 136(Suppl 1):12-14

95 Herviou L, Kassambara A, Boireau S, et al. PRC2 targeting is a therapeutic strategy for EZ score defined high-risk multiple myeloma patients and overcome resistance to IMiDs. Clin Epigenetics 2018;10(01):121

96 Kaiser MF, Johnson DC, Wu P, et al. Global methylation analysis identifies prognostically important epigenetically inactivated tumor suppressor genes in multiple myeloma. Blood 2013;122 (02):219-226

97 Barwick BG, Skerget S, Keats JJ, et al. Multiple myeloma epigenetic programming prognostic of outcome converges with loci reprogrammed in relapsed/refractory disease. Blood 2019;134 (Suppl 1):858

98 Pawlyn C, Kaiser MF, Heuck C, et al. The spectrum and clinical impact of epigenetic modifier mutations in myeloma. Clin Cancer Res 2016;22(23):5783-5794 